\title{
Prevalence and determinants of cervical cancer awareness among women of reproductive age: evidence from Benin and Zimbabwe population-based data
}

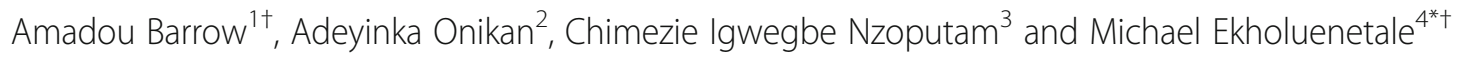

\begin{abstract}
Background: Cervical cancer is a prominently diagnosed form of cancer in several resource-constrained settings particularly within the sub-Saharan African region. Globally, Africa region has the highest incidence and mortality rates of cervical cancer. The high prevalence has been attributed to several factors including lack of awareness of the disease. The aim of this paper is to explore the prevalence and factors associated with awareness of cervical cancer among women of reproductive age in Republic of Benin and Zimbabwe, sub-Saharan Africa.

Methods: We used population-based cross-sectional data from Benin Demographic and Health Survey (BDHS) and Zimbabwe Demographic and Health Survey (ZDHS) respectively. BDHS 2017-18 and ZDHS - 2015 are the 5th and 6 th rounds of the surveys respectively. About 15,928 and 9955 women aged 15-49 years were included in this study respectively. The awareness of cervical cancer among women of reproductive age in Benin and Zimbabwe was measured dichotomously; yes (if a woman heard of cervical cancer) vs. no (if a woman has not heard of cervical cancer). All significant variables from the bivariate analysis were included in the multivariable logistic regression model to calculate the adjusted odds ratios (AOR) with corresponding 95\% confidence interval.

(Continued on next page)
\end{abstract}

\footnotetext{
* Correspondence: mic42006@gmail.com

${ }^{\dagger}$ Amadou Barrow and Michael Ekholuenetale are authors contributed equally and are joint first authors.

${ }^{4}$ Department of Epidemiology and Medical Statistics, Faculty of Public Health,

College of Medicine, University of Ibadan, Ibadan, Nigeria

Full list of author information is available at the end of the article
}

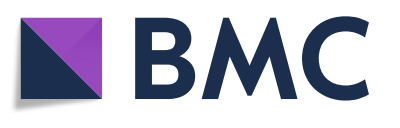

(c) The Author(s). 2020 Open Access This article is licensed under a Creative Commons Attribution 4.0 International License, which permits use, sharing, adaptation, distribution and reproduction in any medium or format, as long as you give appropriate credit to the original author(s) and the source, provide a link to the Creative Commons licence, and indicate if changes were made. The images or other third party material in this article are included in the article's Creative Commons licence, unless indicated otherwise in a credit line to the material. If material is not included in the article's Creative Commons licence and your intended use is not permitted by statutory regulation or exceeds the permitted use, you will need to obtain permission directly from the copyright holder. To view a copy of this licence, visit http://creativecommons.org/licenses/by/4.0/. 
(Continued from previous page)

Results: While majority (79.2\%) of women from Zimbabwe have heard about cervical cancer, only about one-tenth (10.2\%) of their Beninese counterparts have heard about the disease. Advanced maternal age, having formal education, use of internet, having professional/technical/managerial occupation significantly increased the odds of awareness of cervical cancer after adjusting for other confounders. However, in Benin, women who resided in the rural area and those of Islamic belief had 20\% (AOR $=0.80 ; 95 \% \mathrm{Cl}: 0.64,0.99)$ and $35 \%(\mathrm{AOR}=0.65 ; 95 \% \mathrm{Cl}$ : $0.50,0.86)$ reduction in the odds of awareness of cervical cancer respectively, when compared with women from urban residence and Christianity. Results from the predictive marginal effects showed that, assuming the distribution of all factors remained the same among women, but every woman is an urban dweller, we would expect 11.0 and $81.0 \%$ level of awareness of cervical cancer; If everywoman had higher education, we would expect 20.0 and $90 \%$ level of awareness of cervical cancer and if instead the distribution of other maternal factors were as observed and other covariates remained the same among women, but all women were in the richest household wealth quintile, we would expect about 11.0 and 83.0\% level of awareness of cervical cancer, among women of reproductive age from Benin and Zimbabwe respectively.

Conclusion: The study has revealed that socio-demographical factors including geographical location and selected economic factors explained the inequality in distribution of women's awareness on cervical cancer in both countries. Designing an effective population-based health education and promotion intervention programs on cervical cancer will be a great way forward to improving women's awareness level on cervical cancer.

Keywords: Knowledge, Human papillomavirus, HPV, Maternal health, Health education, Africa

\section{Background}

Cervical cancer has been reported to be the fourth most commonly detected cancer among women globally [1]. It ranks second behind breast cancer as the most incident and mortal cancer among women in lower human development index (HDI) settings. It is also the most commonly diagnosed cancer in 28 countries and the leading cause of cancer death in 42 countries, with majority of which are sub-Saharan Africa (SSA) and South Eastern Asia [1]. Africa has the highest incidence and mortality rates of cervical cancer among other regions of the world; the rates are elevated in the Southern Africa countries with Swaziland having the highest incidence rate; followed by Eastern Africa with Malawi having the highest rate of death followed by Zimbabwe; and Western Africa, with Guinea, Burkina Faso, and Mali taking the lead in that order [1]. Nearly $80 \%$ of all cervical cancers and $90 \%$ of deaths occur in the poor-resource countries of the world with SSA bearing the highest burden [2]. It was also estimated that if cervical cancer prevention, screening and treatment are not immediately and urgently scaled up, there could be a 50\% increase in mortality over 2018 levels by 2040 [2]. Unfortunately, the west African region has a total annual new cases of cervical cancer of 31,955 at a crude incidence and age-standardized rates of 16.8 and 29.6 (cases of cancer per 100,000 women per year) [3].

In 2014, the World Health Organization (WHO) published an updated guideline from the previous 2006 guideline on the prevention and control of cervical cancer [4]. This was to be achieved through community mobilization, education and counseling, vaccination of girls 9-13 years against the major known cause of cervical cancer, Human Papilloma Virus (HPV), screening and treatment of cervical pre-cancer, diagnosis and treatment of invasive cervical cancer and provision of palliative care to patients with cervical cancer [4]. It is against this backdrop that all member nations especially poor-resource countries are encouraged to key into this guideline to make sure that the burden of cervical cancer is effectively reduced. A strict adherence to this guideline will ensure that the Sustainable Development Goals 3 (especially 3.3, 3.4, 3.7 and 3.8) of the United Nations that advocates for good healthy living and promotion of wellbeing for all at all ages [5], will be met.

Several factors have been identified to be associated with cervical cancer; these include poor cervical cancer screening, lack of awareness and knowledge of cervical cancer; biological factors such as poor nutrition, infections with human immunodeficiency virus (HIV), tuberculosis (TB), malaria; socioeconomic and socio-cultural factors with political inequities, have been implicated in the high prevalence of cervical cancer in SSA countries [6]. Though cervical cancer is the most common cancer among women living with HIV, persistent infection with HPV has been implicated as the most common cause of the cancer of the cervix. Women living with HIV are up to five times more likely to develop invasive cervical cancer than other women. In SSA, cervical cancer is reportedly a prominent cancer killer of women [6].

Cervical cancer is known to be the most frequently diagnosed cancer amongst Zimbabwean women and it accounts for about a third of all cancers in this Zimbabwean key population [7]. Report has shown that 3186 new cases of cervical cancer and 2151 deaths occur 
as a result of the disease every year in Zimbabwe [8]. This data projects that about 4.5 million Zimbabwean women are at the risk of cervical cancer in their life time [9]. Evidence shows that only about a third of Zimbabwean women had ever been screened for cervical cancer and affiliation to major religious groups and non-visit to health facilities were negative contributory factors to poor screening uptake [10]. Furthermore, in the republic of Benin, just as in many other SSA countries, the issue of cervical cancer is still a great public health problem. Though there are no available data from Cancer Registry in Benin for cervical cancer [3], Globocon 2018 and International Agency for Research in Cancer (IARC) 2019 survey data show that cervical cancer ranks the third most incident and most prevalent cancer among Beninese after breast cancer and prostate cancer in that order, with an annual new diagnosed cases of 783 and the second most common cancer and cause of cancer death, with annual death of 652 among Beninese women $[1,3,11]$. The death rate caused by cervical cancer is number 3 among all types of cancer. The agestandardized rate in terms of incidence among the female Beninese population is about one-quarters $[1,3$, $11]$.

SSA region has the highest incidence rate of cervical cancer when compared with other regions of the world, with associated high mortality affecting women at their prime [6]. Screening programs are grossly inadequate or non-available thereby making early detection of precancerous lesions inefficient or in many instances practically impossible, within the countries in the region. Most screening activities are done as pilot or research projects which are discontinued on completion [6]. This has made awareness of cervical cancer, its screening and risk factors among the women population in most parts of this region very poor, thereby resulting in high incidence, prevalence, and mortality rate $[1,3,8,11]$. In the light of the above, we undertake this paper to explore the prevalence and factors associated with awareness of cervical cancer among women of reproductive age in Republic of Benin and Zimbabwe, sub-Saharan Africa.

\section{Methods}

\section{Data extractionges}

We used population-based cross-sectional data from Benin Demographic and Health Survey (BDHS) and Zimbabwe Demographic and Health Survey (ZDHS) respectively. BDHS 2017-18 and ZDHS - 2015 are the 5th and 6th rounds of the surveys respectively. About 15,928 and 9955 women of reproductive age from Benin and Zimbabwe were included in this study respectively. By implication, the data analyzed in this study included women aged 15-49 years. BDHS and ZDHS have response rates of 98.1 and $96.2 \%$ respectively. The data is available in the public domain and accessed at; http:// dhsprogram.com/data/available-datasets.cfm.

\section{Study design}

DHS project is funded by the United States Agency for International Development (USAID) with support from other donors and host countries, has conducted over 230 nationally representative and internationally comparable household surveys in more than 80 countries since its inception in 1984. The first three of the DHS's six phases were implemented between 1984 and 1997. Thereafter the project was folded into a family of USAID monitoring and evaluation projects and was renamed MEASURE DHS. DHS originally collected comparable population-based data on fertility, contraception, maternal and child health and nutrition in developing countries. Today, DHS core questionnaires cover a wider range of population and health topics. DHS used a twostage stratified cluster sampling method to select enumeration areas (EAs) and household samples. The first stage involves the selection of EAs with probability proportional to the size. Secondly, from the total residential households selected, a number of households were selected per EA. All women of reproductive age (15 to 49 years) were selected for the component of the survey including respondents' characteristics. The survey design, sampling technique, data collection instruments, data quality assurance, ethical approval and subject consent for DHS were conducted appropriately in line with international standard $[12,13]$. The DHS were initially designed to expand on demographic, fertility and family planning data collected in the World Fertility Surveys and Contraceptive Prevalence Surveys, but continue to provide an important resource for the monitoring of vital statistics and population health indicators. DHS collects a wide range of data with a focus on indicators of fertility, reproductive health, maternal and child health, mortality, nutrition and health behaviours. DHS data is useful in public health research focused on monitoring of prevalence, trends and inequalities. During the survey, multi-stage stratified cluster sampling approach was used to select the respondents based on allocation of specific numbers of clusters to urban and rural settlements in the country. Different questionnaires were designed to obtain information related to women, men, households, children and couples. The reliability and validity of the questionnaires were well conducted using standard methods. An overview of the DHS along with an introduction to the potential scope for these data is reported elsewhere.

\section{Study area}

The geographical regions in Benin, include; Alibori, Atacora, Atlantique, Borgou, Collines, Couffo, Donga, Littoral, Mono, Quémé, Plateau and Zou. The country 
spans from north to south and a long stretched country in West Africa, located west of Nigeria and east of Togo, it is bordered to the north by Niger and Burkina Faso, in south by the Bight of Benin, in the Gulf of Guinea, that part of the tropical North Atlantic Ocean which is roughly south of West Africa. Benin's coastline is approximately $121 \mathrm{~km}$ long, with an area of $112,622 \mathrm{~km}^{2}$. Benin's former name, until 1975, was Dahomey. Benin has a population of 10 million people (in 2013), PortoNovo, a port on an inlet of the Gulf of Guinea is the nation's capital city, largest city and economic capital is Cotonou. Spoken languages are French (official), Fon and Yoruba [14]. Furthermore, Zimbabwe has nine [9] geographical regions, namely; Manicaland, Manicaland Central, Manicaland East, Manicaland West, Manicaland North, Manicaland South, Midlands, Masvingo, Harare \& Bulawayo. Zimbabwe is a landlocked country in southern Africa lying wholly within the tropics. It has a total land area of about $390,000 \mathrm{~km}^{2}$ and a population of about 15 million. It shares a $125-$ mile $(200-\mathrm{km})$ border on the south with the Republic of South Africa and is bounded on the southwest and west by Botswana, on the north by Zambia, and on the northeast and east by Mozambique. The capital is Harare (formerly called Salisbury). More than twothirds of Zimbabweans speak Shona as their first language, while about one out of six speak Ndebele [15].

\section{Outcome variable}

The awareness of cervical cancer among women of reproductive age in Benin and Zimbabwe was measured dichotomously; yes (if a woman heard of cervical cancer) vs. no (if a woman has not heard of cervical cancer).

\section{Explanatory variables}

Age (years) of respondent: 15-19, 20-24, 25-29, 30-34, 35-39, 40-44, 45-49; residential status: urban vs. rural; educational attainment: no formal education, primary, secondary, higher; religious background: Christianity, Islam, traditional/others; literacy: cannot read at all/able to read only part of sentence, able to read whole sentence; read newspaper: not at all, less than once a week, at least once a week; listen to radio: not at all, less than once a week, at least once a week; watch TV: not at all, less than once a week, at least once a week; marital status: never in union, currently in union/living with a man, formerly in union/lived with a man; occupation: not working, professional/technical/managerial, sales, agricultural, services, skilled manual; geographical region: Benin: $1=$ Alibori, $2=$ Atacora, $3=$ Atlantic, $4=$ Borgou, $5=$ Collines, $6=$ Couffo, $7=$ Donga, $8=$ Littoral, $9=$ Mono,$\quad 10=$ Oueme,$\quad 11=$ Plateau \& $12=$ Zou; Zimbabwe: 1 = Manicaland, 2 = Manicaland Central, 3 = Manicaland East, $4=$ Manicaland West, $5=$ Manicaland North, $6=$ Manicaland South, $\quad 7=$ Midlands, $\quad 8=$
Masvingo, $9=$ Harare \& $10=$ Bulawayo. These factors were included based on previous studies that examined the factors associated with awareness of cervical cancer [16-18]. Household wealth quintile: principal components analysis (PCA) was used to assign the wealth indicator weights. This procedure assigned scores and standardized the wealth indicator variables such as; bicycle, motorcycle/scooter, car/truck, main floor material, main wall material, main roof material, sanitation facilities, water source, radio, television, electricity, refrigerator, cooking fuel, furniture, number of persons per room. The factor coefficient scores (factor loadings) and z-scores were calculated. For each household, the indicator values were multiplied by the loadings and summed to produce the household's wealth index value. The standardized z-score was used to disentangle the overall assigned scores to poorest/poorer/middle/richer/richest categories $[19,20]$.

\section{Ethical consideration}

This study was based on an analysis of population-based dataset available in public domain/ online with all identifier information removed. The authors communicated with MEASURE DHS/ICF International and permission was granted to download and use the data. The DHS project obtained the required ethical approvals from the relevant research ethics committee in Benin and Zimbabwe, before the survey was conducted to ensure that the protocols are in compliance with the U.S. Department of Health and Human Services regulations for the protection of human subjects. Written informed consents were obtained from participants before being allowed in the surveys.

\section{Statistical analysis}

In Stata, the Survey ('svy') module was used to adjust for stratification, clustering and sampling weights to compute the estimates of awareness on cervical cancer. The collinearity testing approach adopted the correlation analysis to detect interdependence between variables. A cut-off of 0.7 was used to examine the multicollinearity known to cause major concerns [21]. No variable from the correlation matrix was removed in the model due to lack of multicollinearity. Women's characteristics were obtained using percentages. Chi-square test was used to examine the association between awareness on cervical and the explanatory variables. All significant variables from the bivariate analysis were included in the multivariable logistic regression model to calculate the adjusted odds ratios (with corresponding 95\%CI). In addition, we obtained the marginal predictive effects of the factors. Based on the estimation of multivariable logistic regression model, we predicted the probability of awareness on cervical cancer. Thus; 


$$
\operatorname{Pr}(Y=1 \mid \operatorname{Set}[\mathrm{E}=\mathrm{e}])=\sum_{\mathrm{z}} \hat{p}_{e z} \operatorname{Pr}(Z=z)
$$

Where Set $[E=e]$ reflects putting all observations to a single exposure level e, and $\mathrm{Z}=\mathrm{z}$ refers to a given set of observed values for the covariate vector $Z$. Furthermore, $\hat{p}_{e z}$ is the predicted probabilities of awareness on cervical cancer for any $\mathrm{E}=\mathrm{e}$ and $\mathrm{Z}=\mathrm{z}$. The marginal effects indicate a weighted average over the distribution of the covariates and are equal to estimates got by standardizing to the entire population. As a post logistic regression test, the exposure $E$ is set to the level $e$ for all women in the dataset, and the logistic regression coefficients are used to compute predicted probabilities for every woman at their observed covariate pattern and newly exposure value. Because predicted probabilities are computed under the same distribution of $Z$, there is no covariate of the corresponding effect measure estimates [22]. Statistical significance was determined at $p<0.05$. Data analysis was conducted using Stata Version 14 (StataCorp., College Station, TX, USA).

\section{Results}

The results from Fig. 1 showed that while majority (79.2\%) of women from Zimbabwe reportedly have heard about cervical, only about one-tenth (10.2\%) of women from Benin have heard about cervical cancer. See Fig. 1 for the details.

The results from Table 1 showed that the proportion of women who have ever heard about cervical cancer somewhat increased by increases in age in both countries. Clearly, women from urban residence, higher educational attainment, able to read whole sentence, read newspaper/ magazine, listen to radio, watch television, use internet, non-poor and have professional/technical/managerial occupation reportedly have higher proportion of ever heard of cervical cancer in Benin and Zimbabwe respectively. In addition, all explanatory variables were statistically significant with awareness of cervical cancer using Chi-square test. See Table 1 for the details.

\section{Determinants of awareness of cervical cancer among women aged 15-49 years in Benin and Zimbabwe}

In Table 2, several factors were statistically significant with awareness of cervical cancer using multivariable logistic regression model. In both countries, advanced maternal age, having formal education, use of internet, having professional/technical/managerial occupation significantly increased the odds of awareness on cervical cancer after adjusting for other confounders. However, in Benin, women who resided in the rural area and those who had Islamic belief had 20\% (OR $=0.80 ; 95 \% \mathrm{CI}$ : $0.64,0.99)$ and $35 \%(\mathrm{OR}=0.65 ; 95 \% \mathrm{CI}: 0.50,0.86)$ reduction in the odds of awareness on cervical cancer respectively, when compared with women from urban residence and Christianity after adjusting for other covariates. Women who watch television had higher odds of awareness on cervical cancer, compared with women who do not watch television at all after adjusting for other covariates. In Zimbabwe, women who are able to read at least part of a sentence, read newspaper/magazine, listen to radio, had increase in the odds of awareness on cervical cancer, when compared with women who cannot read at all, do not read newspaper/ magazine, do not listen to radio after adjusting for other confounders. Furthermore, increased household wealth quintile level and ever being married increased the odds of awareness on cervical cancer among women, when compared with women from poorest household and those who were never in union after adjusting for other covariates. See Table 2 for the details.

\section{Predictive marginal effects of the factors associated with awareness of cervical cancer among women aged 15-49 years in Benin and Zimbabwe}

In Table 3, marginal effect analysis was used to decipher the effects of the factors associated with awareness of cervical cancer among women of reproductive age in Benin and Zimbabwe. Overall, advanced maternal age, urban residence, higher education, Christianity faith,

- Heard of cervical cancer $\quad$ Screened of cervical cancer

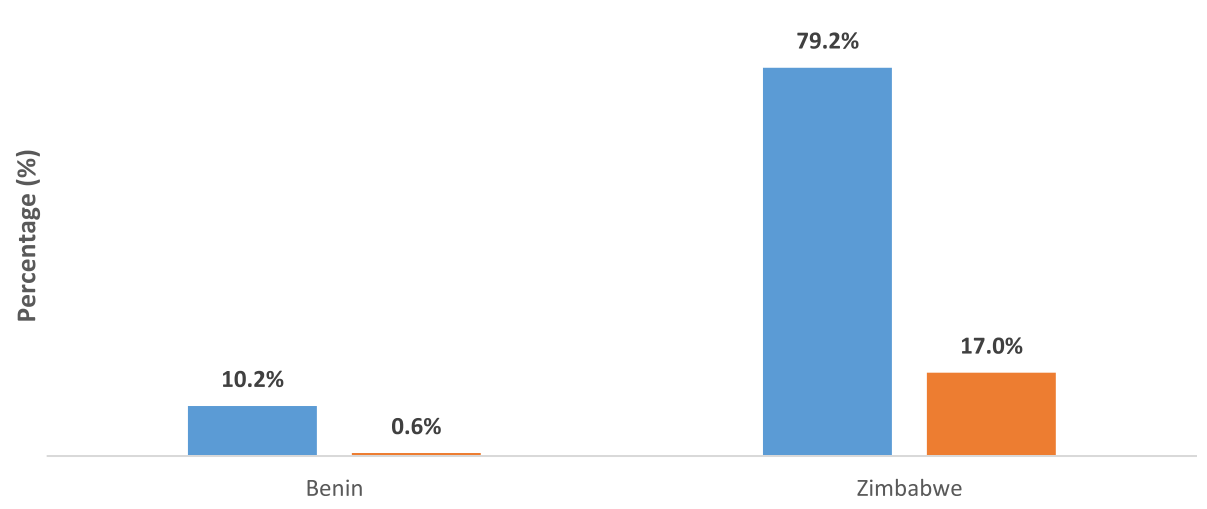

Fig. 1 Awareness and screening of cervical cancer among women of age in Benin and Zimbabwe 
Table 1 Awareness of cervical cancer among women of reproductive age in Benin and Zimbabwe, sub-Saharan Africa

\begin{tabular}{|c|c|c|c|c|c|c|c|c|}
\hline \multirow[t]{3}{*}{ Variable } & \multicolumn{4}{|l|}{ Benin } & \multicolumn{4}{|l|}{ Zimbabwe } \\
\hline & \multirow[t]{2}{*}{ n (\%) } & \multicolumn{2}{|c|}{$\begin{array}{l}\text { Heard about cervical } \\
\text { cancer }\end{array}$} & \multirow[t]{2}{*}{$\mathrm{p}$} & \multirow[t]{2}{*}{$\mathrm{n}(\%)$} & \multicolumn{2}{|c|}{$\begin{array}{l}\text { Heard about cervical } \\
\text { cancer }\end{array}$} & \multirow[t]{2}{*}{$\mathrm{p}$} \\
\hline & & No (\%) & Yes (\%) & & & No (\%) & Yes (\%) & \\
\hline Age (years) of respondent & & & & $<0.001^{*}$ & & & & $<0.001^{*}$ \\
\hline $15-19$ & $3335(20.9)$ & 93.7 & 6.3 & & $2156(21.7)$ & 43.2 & 56.8 & \\
\hline $20-24$ & $2916(18.3)$ & 88.8 & 11.2 & & $1782(17.9)$ & 22.7 & 77.3 & \\
\hline $25-29$ & $2971(18.7)$ & 88.0 & 12.0 & & $1656(16.6)$ & 15.0 & 85.0 & \\
\hline $30-34$ & $2195(13.8)$ & 89.6 & 10.4 & & $1591(16.0)$ & 11.1 & 88.9 & \\
\hline $35-39$ & $1905(12.0)$ & 89.5 & 10.5 & & $1209(12.1)$ & 10.7 & 89.3 & \\
\hline $40-44$ & $1333(8.4)$ & 87.9 & 12.1 & & $966(9.7)$ & 10.7 & 89.3 & \\
\hline $45-49$ & $1273(8.0)$ & 89.4 & 10.6 & & $595(6.0)$ & 12.3 & 87.7 & \\
\hline Residential status & & & & $<0.001^{*}$ & & & & $<0.001^{*}$ \\
\hline Urban & $7045(44.2)$ & 84.9 & 15.1 & & $4521(45.4)$ & 12.4 & 87.6 & \\
\hline Rural & $8883(55.8)$ & 93.8 & 6.2 & & $5434(54.6)$ & 27.7 & 72.3 & \\
\hline Education level & & & & $<0.001^{*}$ & & & & $<0.001^{*}$ \\
\hline None & $8762(55.0)$ & 95.0 & 5.0 & & $106(1.1)$ & 40.6 & 59.4 & \\
\hline Primary & 3116 (19.6) & 91.0 & 9.0 & & $2385(24.0)$ & 33.3 & 66.7 & \\
\hline Secondary & $3685(23.1)$ & 81.0 & 19.0 & & $6637(66.7)$ & 18.3 & 81.7 & \\
\hline Higher & $365(2.3)$ & 48.1 & 51.9 & & $827(8.3)$ & 2.1 & 97.9 & \\
\hline Religious belief & & & & $<0.001^{*}$ & & & & $0.002^{*}$ \\
\hline Christianity & $8784(55.1)$ & 86.1 & 13.9 & & $9385(94.3)$ & 20.4 & 79.6 & \\
\hline Islam & 4677 (29.4) & 94.9 & 5.1 & & $30(0.3)$ & 20.0 & 80.0 & \\
\hline Traditional/others & 2467 (15.5) & 93.3 & 6.7 & & $540(5.4)$ & 26.9 & 73.1 & \\
\hline Literacy & & & & $<0.001^{*}$ & & & & $<0.001^{*}$ \\
\hline Cannot read at all & $10,359(65.4)$ & 94.3 & 5.7 & & $495(5.0)$ & 44.2 & 55.8 & \\
\hline Able to read only part of sentence & $1133(7.1)$ & 91.6 & 8.4 & & $734(7.4)$ & 28.2 & 71.8 & \\
\hline Able to read whole sentence & $4357(27.5)$ & 78.6 & 21.4 & & $8698(87.6)$ & 18.7 & 81.3 & \\
\hline Frequency of reading newspaper/magazine & & & & $<0.001^{*}$ & & & & $<0.001^{*}$ \\
\hline Not at all & $14,419(90.5)$ & 91.4 & 8.6 & & $5446(54.7)$ & 28.1 & 71.9 & \\
\hline Less than once a week & $878(5.5)$ & 73.9 & 26.1 & & $2778(27.9)$ & 13.4 & 86.6 & \\
\hline At least once a week & $631(4.0)$ & 76.7 & 23.3 & & $1731(17.4)$ & 9.5 & 90.5 & \\
\hline Frequency of listening to radio & & & & $<0.001^{*}$ & & & & $<0.001^{*}$ \\
\hline Not at all & $6840(42.9)$ & 94.1 & 5.9 & & $4482(45.0)$ & 26.8 & 73.2 & \\
\hline Less than once a week & $3408(21.4)$ & 89.7 & 10.3 & & $2112(21.2)$ & 19.0 & 81.0 & \\
\hline At least once a week & $5680(35.7)$ & 84.8 & 15.2 & & $3361(33.8)$ & 13.7 & 86.3 & \\
\hline Frequency of watching television & & & & $<0.001^{*}$ & & & & $<0.001^{*}$ \\
\hline Not at all & $9775(61.4)$ & 94.5 & 5.5 & & $5054(50.8)$ & 27.1 & 72.9 & \\
\hline Less than once a week & $2741(17.2)$ & 87.6 & 12.4 & & $1381(13.9)$ & 17.3 & 82.7 & \\
\hline At least once a week & $3412(21.4)$ & 78.0 & 22.0 & & $3520(35.4)$ & 12.9 & 87.1 & \\
\hline Frequency of using internet & & & & $<0.001^{*}$ & & & & $<0.001^{*}$ \\
\hline Not at all & $14,845(93.2)$ & 92.2 & 7.8 & & $7325(73.6)$ & 25.4 & 74.6 & \\
\hline Less than once a week & $141(0.9)$ & 70.8 & 29.2 & & $214(2.1)$ & 12.1 & 87.9 & \\
\hline At least once a week & $281(1.8)$ & 68.6 & 31.4 & & $413(4.1)$ & 10.2 & 89.8 & \\
\hline Almost every day & $661(4.1)$ & 50.5 & 49.5 & & $2003(20.1)$ & 7.0 & 93.0 & \\
\hline Wealth quintile & & & & $<0.001^{*}$ & & & & $<0.001^{*}$ \\
\hline
\end{tabular}


Table 1 Awareness of cervical cancer among women of reproductive age in Benin and Zimbabwe, sub-Saharan Africa (Continued)

\begin{tabular}{|c|c|c|c|c|c|c|c|c|}
\hline \multirow[t]{3}{*}{ Variable } & \multicolumn{4}{|l|}{ Benin } & \multicolumn{4}{|l|}{ Zimbabwe } \\
\hline & \multirow[t]{2}{*}{ n (\%) } & \multicolumn{2}{|c|}{$\begin{array}{l}\text { Heard about cervical } \\
\text { cancer }\end{array}$} & \multirow[t]{2}{*}{$p$} & \multirow[t]{2}{*}{ n (\%) } & \multicolumn{2}{|c|}{$\begin{array}{l}\text { Heard about cervical } \\
\text { cancer }\end{array}$} & \multirow[t]{2}{*}{$\mathrm{p}$} \\
\hline & & No (\%) & Yes (\%) & & & No (\%) & Yes (\%) & \\
\hline Poorest & $2856(17.9)$ & 96.3 & 3.7 & & $1499(15.1)$ & 36.4 & 63.6 & \\
\hline Poorer & $2976(18.7)$ & 95.4 & 4.6 & & $1452(14.6)$ & 28.6 & 71.4 & \\
\hline Middle & $2985(18.7)$ & 92.7 & 7.3 & & $1549(15.6)$ & 24.7 & 75.3 & \\
\hline Richer & $3281(20.6)$ & 90.5 & 9.5 & & $2558(25.7)$ & 15.4 & 84.6 & \\
\hline Richest & $3830(24.0)$ & 77.3 & 22.7 & & $2897(29.1)$ & 11.3 & 88.7 & \\
\hline Marital status & & & & $<0.001^{*}$ & & & & $<0.001^{*}$ \\
\hline Never in union & $3897(24.5)$ & 88.5 & 11.5 & & $2666(26.8)$ & 35.3 & 64.7 & \\
\hline Currently in union/living with a man & $11,170(70.1)$ & 90.7 & 9.3 & & $6015(60.4)$ & 15.5 & 84.5 & \\
\hline Formerly in union/lived with a man & $861(5.4)$ & 84.3 & 15.7 & & $1274(12.8)$ & 15.1 & 84.9 & \\
\hline Occupation & & & & $<0.001^{*}$ & & & & $<0.001^{*}$ \\
\hline Not working & $3527(23.0)$ & 91.7 & 8.3 & & $4897(54.3)$ & 27.8 & 72.2 & \\
\hline Professional/technical/managerial & $543(3.5)$ & 60.8 & 39.2 & & $615(6.8)$ & 2.4 & 97.6 & \\
\hline Sales & $4537(29.6)$ & 87.7 & 12.3 & & $1794(19.9)$ & 12.5 & 87.5 & \\
\hline Agricultural & $3065(20.0)$ & 97.0 & 3.0 & & $742(8.2)$ & 18.3 & 81.7 & \\
\hline Services & $1842(12.0)$ & 86.5 & 13.5 & & $728(8.1)$ & 11.7 & 88.3 & \\
\hline Skilled manual & $1825(11.9)$ & 93.8 & 6.2 & & $249(2.8)$ & 14.9 & 85.1 & \\
\hline Geographical region & & & & $<0.001^{*}$ & & & & $<0.001^{*}$ \\
\hline 1 & $1697(10.7)$ & 96.4 & 3.6 & & 1019 (10.2) & 23.2 & 76.8 & \\
\hline 2 & $1392(8.7)$ & 91.6 & 8.4 & & $993(10.0)$ & 18.2 & 81.2 & \\
\hline 3 & $1702(10.7)$ & 85.4 & 14.6 & & $910(9.1)$ & 17.1 & 82.9 & \\
\hline 4 & 1765 (11.1) & 98.6 & 1.4 & & 1054 (10.6) & 16.3 & 83.7 & \\
\hline 5 & 1403 (8.8) & 87.3 & 12.7 & & 849 (8.5) & 32.4 & 67.6 & \\
\hline 6 & $1012(6.4)$ & 89.9 & 10.1 & & 829 (8.3) & 34.3 & 65.7 & \\
\hline 7 & $964(6.1)$ & 94.5 & 5.5 & & $1062(10.7)$ & 24.3 & 75.7 & \\
\hline 8 & 1415 (8.9) & 70.3 & 29.7 & & $1046(10.5)$ & 24.2 & 75.8 & \\
\hline 9 & $816(5.1)$ & 87.9 & 12.1 & & 1235 (12.4) & 9.1 & 90.9 & \\
\hline 10 & 1260 (7.9) & 92.0 & 8.0 & & 958 (9.6) & 14.5 & 85.5 & \\
\hline 11 & $952(6.0)$ & 95.5 & 4.5 & & & & & \\
\hline 12 & $1550(9.7)$ & 88.0 & 12.0 & & & & & \\
\hline
\end{tabular}

Benin: 1 = Alibori, $2=$ Atacora, $3=$ Atlantic, $4=$ Borgou, $5=$ Collines, $6=$ Couffo, $7=$ Donga, $8=$ Littoral, $9=$ Mono, $10=$ Oueme, $11=$ Plateau \& $12=$ Zou.

Zimbabwe: $1=$ Manicaland, $2=$ Manicaland Central, $3=$ Manicaland East, $4=$ Manicaland West, $5=$ Manicaland North, $6=$ Manicaland South, $7=$ Midlands, $8=$

Masvingo, $9=$ Harare \& $10=$ Bulawayo.

*Significant at $p<0.005$

ability to read whole sentence and/or newspaper or magazine, listening to radio at least once a week, watching television at least once a week, using internet almost every day, richest households and professional/technical/ managerial occupation have higher marginal effects of awareness of cervical cancer among women of reproductive age from Benin and Zimbabwe respectively. Clearly, from the predictive marginal effects results, assuming the distribution of all factors remained the same among women, but every woman is an urban dweller, we would expect 11.0 and $81.0 \%$ level of awareness of cervical cancer among women of reproductive age from Benin and Zimbabwe respectively. If everywoman had higher education, we would expect 20.0 and $90 \%$ level of awareness of cervical cancer among women of reproductive age from Benin and Zimbabwe respectively. If instead the distribution of other maternal factors were as observed and other covariates remained the same among women, but all women were in the richest household wealth quintile, we would expect about 11.0 and $83.0 \%$ level of awareness of cervical cancer among women of reproductive age from Benin and Zimbabwe respectively. 
Table 2 Factors associated with awareness of cervical cancer among women of reproductive age in Benin and Zimbabwe, subSaharan Africa

\begin{tabular}{|c|c|c|c|c|}
\hline \multirow[t]{2}{*}{ Variable } & \multicolumn{2}{|l|}{ Benin } & \multicolumn{2}{|l|}{ Zimbabwe } \\
\hline & Adjusted odds ratio $(95 \% \mathrm{Cl})$ & $\mathbf{P}$ & Adjusted odds ratio $(95 \% \mathrm{Cl})$ & $\mathbf{P}$ \\
\hline \multicolumn{5}{|l|}{ Age (years) of respondent (ref: 15-19) } \\
\hline $20-24$ & $1.99(1.42-2.78)$ & $<0.001^{*}$ & $1.77(1.46-2.14)$ & $<0.001^{*}$ \\
\hline $25-29$ & $2.51(1.72-3.67)$ & $<0.001^{*}$ & $2.80(2.24-3.51)$ & $<0.001^{*}$ \\
\hline $30-34$ & $2.48(1.62-3.80)$ & $<0.001^{*}$ & $3.89(3.06-4.93)$ & $<0.001^{*}$ \\
\hline $35-39$ & $2.74(1.78-4.25)$ & $<0.001^{*}$ & $4.49(3.44-5.85)$ & $<0.001^{*}$ \\
\hline $40-44$ & $3.91(2.47-6.17)$ & $<0.001^{*}$ & $4.58(3.45-6.09)$ & $<0.001^{*}$ \\
\hline $45-49$ & $3.11(1.96-4.95)$ & $<0.001^{*}$ & $5.01(3.61-6.96)$ & $<0.001^{*}$ \\
\hline \multicolumn{5}{|l|}{ Residential status (ref: Urban) } \\
\hline Rural & $0.80(0.64-0.99)$ & $0.043^{*}$ & $0.80(0.62-1.03)$ & 0.084 \\
\hline \multicolumn{5}{|l|}{ Education level (ref: None) } \\
\hline Primary & $1.34(1.01-1.81)$ & $0.049^{*}$ & $1.50(0.93-2.40)$ & 0.097 \\
\hline Secondary & $2.53(1.70-3.78)$ & $<0.001^{*}$ & $2.91(1.78-4.76)$ & $<0.001^{*}$ \\
\hline Higher & $4.19(2.36-7.44)$ & $<0.001^{*}$ & $6.34(2.98-13.46)$ & $<0.001^{*}$ \\
\hline \multicolumn{5}{|l|}{ Religious belief (ref: Christianity) } \\
\hline Islam & $0.65(0.50-0.86)$ & $0.002^{*}$ & $0.50(0.19-1.33)$ & 0.165 \\
\hline Traditional/others & $0.85(0.64-1.13)$ & 0.258 & $0.94(0.74-1.19)$ & 0.606 \\
\hline \multicolumn{5}{|l|}{ Literacy (ref: Cannot read at all) } \\
\hline Able to read only part of sentence & $0.88(0.59-1.31)$ & 0.526 & $1.93(1.43-2.59)$ & $<0.001^{*}$ \\
\hline Able to read whole sentence & $1.12(0.78-1.59)$ & 0.545 & $1.63(1.27-2.08)$ & $<0.001^{*}$ \\
\hline \multicolumn{5}{|c|}{ Frequency of reading newspaper/magazine (ref: Not at all) } \\
\hline Less than once a week & $0.99(0.73-1.35)$ & 0.968 & $1.68(1.43-1.96)$ & $<0.001^{*}$ \\
\hline At least once a week & $0.70(0.48-1.03)$ & 0.068 & $1.59(1.28-1.98)$ & $<0.001^{*}$ \\
\hline \multicolumn{5}{|c|}{ Frequency of listening to radio (ref: Not at all) } \\
\hline Less than once a week & $1.07(0.83-1.38)$ & 0.608 & $1.07(0.92-1.26)$ & 0.365 \\
\hline At least once a week & $1.21(0.96-1.52)$ & 0.100 & $1.59(1.37-1.84)$ & $<0.001^{*}$ \\
\hline \multicolumn{5}{|c|}{ Frequency of watching television (ref: Not at all) } \\
\hline Less than once a week & $1.50(1.16-1.93)$ & $0.002^{*}$ & $1.14(0.94-1.38)$ & 0.194 \\
\hline At least once a week & $1.44(1.10-1.89)$ & $0.008^{*}$ & $1.05(0.87-1.27)$ & 0.586 \\
\hline \multicolumn{5}{|c|}{ Frequency of using internet (ref: Not at all) } \\
\hline Less than once a week & $2.40(1.25-4.59)$ & $0.008^{*}$ & $1.68(1.02-2.76)$ & $0.042^{*}$ \\
\hline At least once a week & $1.83(1.17-2.84)$ & $0.008^{*}$ & $1.52(1.06-2.20)$ & $0.023^{*}$ \\
\hline Almost every day & $2.77(1.96-3.93)$ & $<0.001^{*}$ & $1.90(1.50-2.39)$ & $<0.001^{*}$ \\
\hline \multicolumn{5}{|l|}{ Wealth quintile (ref: Poorest) } \\
\hline Poorer & $0.88(0.60-1.30)$ & 0.529 & $1.20(1.01-1.43)$ & $0.050^{*}$ \\
\hline Middle & $1.09(0.75-1.58)$ & 0.660 & $1.30(1.08-1.57)$ & $0.007^{*}$ \\
\hline Richer & $1.06(0.72-1.53)$ & 0.766 & $1.45(1.13-1.88)$ & $0.004^{*}$ \\
\hline Richest & $1.21(0.81-1.82)$ & 0.356 & $1.68(1.20-2.34)$ & $0.002^{*}$ \\
\hline \multicolumn{5}{|l|}{ Marital status (ref: Never in union) } \\
\hline Currently in union/living with a man & $0.86(0.65-1.15)$ & 0.321 & $1.95(1.63-2.33)$ & $<0.001^{*}$ \\
\hline Formerly in union/lived with a man & $1.05(0.68-1.60)$ & 0.832 & $1.83(1.42-2.36)$ & $<0.001^{*}$ \\
\hline \multicolumn{5}{|l|}{ Occupation (ref: Not working) } \\
\hline Professional/technical/managerial & $1.74(1.20-2.54)$ & $0.004^{*}$ & $2.24(1.27-3.95)$ & $0.005^{*}$ \\
\hline
\end{tabular}


Table 2 Factors associated with awareness of cervical cancer among women of reproductive age in Benin and Zimbabwe, subSaharan Africa (Continued)

\begin{tabular}{|c|c|c|c|c|}
\hline \multirow[t]{2}{*}{ Variable } & \multicolumn{2}{|l|}{ Benin } & \multicolumn{2}{|l|}{ Zimbabwe } \\
\hline & Adjusted odds ratio $(95 \% \mathrm{Cl})$ & $\mathbf{P}$ & Adjusted odds ratio $(95 \% \mathrm{Cl})$ & $\mathbf{P}$ \\
\hline Sales & $1.45(1.11-1.91)$ & $0.007^{*}$ & $1.17(0.98-1.39)$ & 0.080 \\
\hline Agricultural & $0.63(0.41-0.95)$ & $0.028^{*}$ & $1.08(0.86-1.35)$ & 0.521 \\
\hline Services & $1.84(1.35-2.50)$ & $<0.001^{*}$ & $1.27(0.98-1.65)$ & 0.074 \\
\hline Skilled manual & $0.91(0.63-1.31)$ & 0.628 & $0.89(0.60-1.33)$ & 0.583 \\
\hline \multicolumn{5}{|c|}{ Geographical region (ref: 1) } \\
\hline 2 & $2.09(1.24-3.51)$ & $0.005^{*}$ & $1.62(1.26-2.08)$ & $<0.001^{*}$ \\
\hline 3 & $1.47(0.90-2.40)$ & 0.127 & $1.39(1.07-1.81)$ & $0.014^{*}$ \\
\hline 4 & $0.22(0.10-0.46)$ & $<0.001^{*}$ & $1.52(1.17-1.95)$ & $0.001^{*}$ \\
\hline 5 & $2.54(1.55-4.17)$ & $<0.001^{*}$ & $0.74(0.58-0.94)$ & $0.016^{*}$ \\
\hline 6 & $2.08(1.22-3.57)$ & $0.007^{*}$ & $0.60(0.47-0.78)$ & $<0.001^{*}$ \\
\hline 7 & $1.22(0.68-2.19)$ & 0.507 & $0.93(0.73-1.18)$ & 0.533 \\
\hline 8 & $1.93(1.18-3.19)$ & $0.009^{*}$ & $0.93(0.74-1.18)$ & 0.576 \\
\hline 9 & $1.53(0.88-2.67)$ & 0.131 & $1.66(1.23-2.23)$ & $0.001^{*}$ \\
\hline 10 & $0.78(0.46-1.33)$ & 0.373 & $0.89(0.66-1.21)$ & 0.465 \\
\hline 11 & $0.66(0.35-1.24)$ & 0.202 & & \\
\hline 12 & $1.67(1.01-2.77)$ & $0.048^{*}$ & & \\
\hline
\end{tabular}

Benin: $1=$ Alibori, $2=$ Atacora, $3=$ Atlantic, $4=$ Borgou, $5=$ Collines, $6=$ Couffo, $7=$ Donga, $8=$ Littoral, $9=$ Mono, $10=$ Oueme, $11=$ Plateau \& $12=$ Zou

Zimbabwe: $1=$ Manicaland, $2=$ Manicaland Central, $3=$ Manicaland East, $4=$ Manicaland West, $5=$ Manicaland North, $6=$ Manicaland South, $7=$ Midlands, $8=$ Masvingo, $9=$ Harare $\& 10=$ Bulawayo.

*Significant at $p<0.05$

In Table 3, we practically obtained the predictive marginal effects of the factors associated with level of awareness of cervical cancer among women of reproductive age from Benin and Zimbabwe respectively. See Table 3 for the details.

\section{Discussion}

This study revealed low awareness of cervical cancer specifically in Benin as opposed to Zimbabwe. It is possible that low literacy levels, poor use of the media, including; listening to radio, watching TV and internet use may have been linked to these findings. This is in line with a systematic review in SSA which stated low awareness of cervical cancer among women [23]. This study demonstrated that in Zimbabwe, although $79.2 \%$ of women had heard of cervical cancer, only $17 \%$ had been screened. Obviously the scenario is still worse in Benin; hence this study becomes crucial to contribute to the knowledge base. Generally, the low level of awareness of cervical cancer has been recognized as one of the factors leading to the high prevalence of cervical cancer in resource-constrained settings compared to the developed world [24]. Women's knowledge of core health issues including prevention and control of cervical cancer has been poor in resource-constrained settings. For example, in a study carried out in two urban slums in Lagos, Nigeria, about one in twenty women were aware of cervical cancer [25], among Ethiopian women of childbearing age, there was low level of awareness [26]; while similar studies in India reported that one in twelve women and one-third of women had heard and were aware of cervical cancer [27, 28].

In this study, the use of print and electronic media were major factors that enhanced awareness of cervical cancer among women. Similar to the findings from previous studies, different media platforms such as radio, print media, internet, TV and organized educational programs positioned women to be advantageous in accessibility to health information [29]; as also found in both Benin and Zimbabwe. It was also found that rural communities are an underserved portion of the population with limited access to health information [30-32]. Awareness of cervical cancer by residential status remarkably varied especially as in the case of Benin Republic. This could be due to the fact that women in rural settings have low knowledge and access to cervical cancer information and services. Health information dissemination is a major growth area for the media, probably because it is in demand by the populace and it is profitable. Nonetheless, media coverage of medical news is generally and may be of diverse quality, especially messages about screening channels and new treatments [33]. The media can have a substantial positive public health role in communicating simple warnings about the 
Table 3 Marginal predictive models of the factors associated with awareness of cervical cancer among women of reproductive age in Benin and Zimbabwe, sub-Saharan Africa

\begin{tabular}{|c|c|c|c|c|}
\hline \multirow[t]{2}{*}{ Variable } & \multicolumn{2}{|l|}{ Benin } & \multicolumn{2}{|l|}{ Zimbabwe } \\
\hline & Marginal effects $(95 \% \mathrm{Cl})$ & $P$ & Marginal effects OR $(95 \% \mathrm{Cl})$ & $P$ \\
\hline \multicolumn{5}{|l|}{ Age (years) of respondent } \\
\hline $15-19$ & $0.05(0.04-0.07)$ & $<0.001^{*}$ & $0.67(0.64-0.69)$ & $<0.001^{*}$ \\
\hline $20-24$ & $0.09(0.08-0.11)$ & $<0.001^{*}$ & $076(0.74-0.78)$ & $<0.001^{*}$ \\
\hline $25-29$ & $0.11(0.10-0.13)$ & $<0.001^{*}$ & $0.83(0.81-0.85)$ & $<0.001^{*}$ \\
\hline $30-34$ & $0.11(0.09-0.13)$ & $<0.001^{*}$ & $0.86(0.84-0.88)$ & $<0.001^{*}$ \\
\hline $35-39$ & $0.12(0.10-0.14)$ & $<0.001^{*}$ & $0.88(0.86-0.90)$ & $<0.001^{*}$ \\
\hline $40-44$ & $0.15(0.12-0.18)$ & $<0.001^{*}$ & $0.88(0.86-0.90)$ & $<0.001^{*}$ \\
\hline $45-49$ & $0.13(0.10-0.16)$ & $<0.001^{*}$ & $0.89(0.86-0.91)$ & $<0.001^{*}$ \\
\hline \multicolumn{5}{|l|}{ Residential status } \\
\hline Urban & $0.11(0.09-0.12)$ & $<0.001^{*}$ & $0.81(0.79-0.84)$ & $<0.001^{*}$ \\
\hline Rural & $0.09(0.08-0.10)$ & $<0.001^{*}$ & $079(0.77-0.80)$ & $<0.001^{*}$ \\
\hline \multicolumn{5}{|l|}{ Education level } \\
\hline None & $0.07(0.06-0.08)$ & $<0.001^{*}$ & $0.66(0.58-0.74)$ & $<0.001^{*}$ \\
\hline Primary & $0.09(0.07-0.10)$ & $<0.001^{*}$ & $0.73(0.71-0.75)$ & $<0.001^{*}$ \\
\hline Secondary & $0.14(0.12-0.17)$ & $<0.001^{*}$ & $0.82(0.81-0.83)$ & $<0.001^{*}$ \\
\hline Higher & $0.20(0.14-0.27)$ & $<0.001^{*}$ & $0.90(0.85-0.94)$ & $<0.001^{*}$ \\
\hline \multicolumn{5}{|l|}{ Religious belief } \\
\hline Christianity & $0.11(0.10-0.12)$ & $<0.001^{*}$ & $0.80(0.79-0.81)$ & $<0.001^{*}$ \\
\hline Islam & $0.08(0.06-0.09)$ & $<0.001^{*}$ & $0.70(0.54-0.85)$ & $<0.001^{*}$ \\
\hline Traditional/others & $0.09(0.08-0.11)$ & $<0.001^{*}$ & $0.79(0.76-0.82)$ & $<0.001^{*}$ \\
\hline \multicolumn{5}{|l|}{ Literacy } \\
\hline Cannot read at all & $0.10(0.08-0.11)$ & $<0.001^{*}$ & $0.73(0.69-0.76)$ & $<0.001^{*}$ \\
\hline Able to read only part of sentence & $0.09(0.06-0.11)$ & $<0.001^{*}$ & $0.82(0.79-0.84)$ & $<0.001^{*}$ \\
\hline Able to read whole sentence & $0.10(0.09-0.12)$ & $<0.001^{*}$ & $0.80(0.79-0.81)$ & $<0.001^{*}$ \\
\hline \multicolumn{5}{|c|}{ Frequency of reading newspaper/magazine } \\
\hline Not at all & $0.10(0.09-0.11)$ & $<0.001^{*}$ & $0.77(0.76-0.78)$ & $<0.001^{*}$ \\
\hline Less than once a week & $0.10(0.08-0.12)$ & $<0.001^{*}$ & $0.84(0.82-0.85)$ & $<0.001^{*}$ \\
\hline At least once a week & $0.08(0.06-0.10)$ & $<0.001^{*}$ & $0.83(0.81-0.85)$ & $<0.001^{*}$ \\
\hline \multicolumn{5}{|l|}{ Frequency of listening to radio } \\
\hline Not at all & $0.09(0.08-0.10)$ & $<0.001^{*}$ & $0.77(0.76-0.79)$ & $<0.001^{*}$ \\
\hline Less than once a week & $0.10(0.08-0.11)$ & $<0.001^{*}$ & $0.78(0.77-0.80)$ & $<0.001^{*}$ \\
\hline At least once a week & $0.11(0.10-0.12)$ & $<0.001^{*}$ & $0.83(0.82-0.85)$ & $<0.001^{*}$ \\
\hline \multicolumn{5}{|l|}{ Frequency of watching television } \\
\hline Not at all & $0.08(0.07-0.09)$ & $<0.001^{*}$ & $0.79(0.78-0.80)$ & $<0.001^{*}$ \\
\hline Less than once a week & $0.11(0.10-0.13)$ & $<0.001^{*}$ & $0.81(0.79-0.83)$ & $<0.001^{*}$ \\
\hline At least once a week & $0.11(0.10-0.13)$ & $<0.001^{*}$ & $0.80(0.78-0.82)$ & $<0.001^{*}$ \\
\hline \multicolumn{5}{|l|}{ Frequency of using internet } \\
\hline Not at all & $0.09(0.08-0.10)$ & $<0.001^{*}$ & $0.78(0.77-0.79)$ & $<0.001^{*}$ \\
\hline Less than once a week & $0.17(0.09-0.25)$ & $<0.001^{*}$ & $0.85(0.79-0.90)$ & $<0.001^{*}$ \\
\hline At least once a week & $0.14(0.10-0.18)$ & $<0.001^{*}$ & $0.84(0.80-0.88)$ & $<0.001^{*}$ \\
\hline Almost every day & $0.19(0.15-0.23)$ & $<0.001^{*}$ & $0.86(0.84-0.88)$ & $<0.001^{*}$ \\
\hline
\end{tabular}


Table 3 Marginal predictive models of the factors associated with awareness of cervical cancer among women of reproductive age in Benin and Zimbabwe, sub-Saharan Africa (Continued)

\begin{tabular}{|c|c|c|c|c|}
\hline \multirow[t]{2}{*}{ Variable } & \multicolumn{2}{|l|}{ Benin } & \multicolumn{2}{|l|}{ Zimbabwe } \\
\hline & Marginal effects $(95 \% \mathrm{Cl})$ & $\mathbf{P}$ & Marginal effects OR $(95 \% \mathrm{Cl})$ & $\mathbf{P}$ \\
\hline Poorest & $0.09(0.07-0.11)$ & $<0.001^{*}$ & $0.76(0.74-0.78)$ & $<0.001^{*}$ \\
\hline Poorer & $0.08(0.06-0.10)$ & $<0.001^{*}$ & $0.78(0.76-0.81)$ & $<0.001^{*}$ \\
\hline Middle & $0.10(0.08-0.12)$ & $<0.001^{*}$ & $0.80(0.77-0.81)$ & $<0.001^{*}$ \\
\hline Richer & $0.10(0.08-0.11)$ & $<0.001^{*}$ & $0.81(0.79-0.83)$ & $<0.001^{*}$ \\
\hline Richest & $0.11(0.09-0.12)$ & $<0.001^{*}$ & $0.83(0.80-0.85)$ & $<0.001^{*}$ \\
\hline \multicolumn{5}{|l|}{ Marital status } \\
\hline Never in union & $0.11(0.09-0.12)$ & $<0.001^{*}$ & $0.73(0.71-0.75)$ & $<0.001^{*}$ \\
\hline Currently in union/living with a man & $0.10(0.09-0.11)$ & $<0.001^{*}$ & $0.82(0.81-0.83)$ & $<0.001^{*}$ \\
\hline Formerly in union/lived with a man & $0.11(0.08-0.14)$ & $<0.001^{*}$ & $0.82(0.79-0.84)$ & $<0.001^{*}$ \\
\hline \multicolumn{5}{|l|}{ Occupation } \\
\hline Not working & $0.08(0.07-0.10)$ & $<0.001^{*}$ & $0.79(0.78-0.80)$ & $<0.001^{*}$ \\
\hline Professional/technical/managerial & $0.13(0.10-0.16)$ & $<0.001^{*}$ & $0.88(0.83-0.93)$ & $<0.001^{*}$ \\
\hline Sales & $0.11(0.10-0.12)$ & $<0.001^{*}$ & $0.81(0.79-0.83)$ & $<0.001^{*}$ \\
\hline Agricultural & $0.06(0.04-0.07)$ & $<0.001^{*}$ & $0.80(0.77-0.82)$ & $<0.001^{*}$ \\
\hline Services & $0.13(0.11-0.15)$ & $<0.001^{*}$ & $0.82(0.79-0.85)$ & $<0.001^{*}$ \\
\hline Skilled manual & $0.08(0.06-0.10)$ & $<0.001^{*}$ & $0.77(0.72-0.83)$ & $<0.001^{*}$ \\
\hline \multicolumn{5}{|l|}{ Geographical region } \\
\hline 1 & $0.08(0.05-0.10)$ & $<0.001^{*}$ & $0.79(0.76-0.81)$ & $<0.001^{*}$ \\
\hline 2 & $0.13(0.10-017)$ & $<0.001^{*}$ & $0.85(0.83-0.87)$ & $<0.001^{*}$ \\
\hline 3 & $0.10(0.08-0.12)$ & $<0.001^{*}$ & $0.83(0.80-0.85)$ & $<0.001^{*}$ \\
\hline 4 & $0.02(0.01-0.03)$ & $0.001^{*}$ & $0.84(0.82-0.86)$ & $<0.001^{*}$ \\
\hline 5 & $0.15(0.12-0.18)$ & $<0.001^{*}$ & $0.74(0.72-0.77)$ & $<0.001^{*}$ \\
\hline 6 & $0.13(0.10-0.16)$ & $<0.001^{*}$ & $0.71(0.68-0.74)$ & $<0.001^{*}$ \\
\hline 7 & $0.09(0.06-0.12)$ & $<0.001^{*}$ & $0.78(0.75-0.80)$ & $<0.001^{*}$ \\
\hline 8 & $0.13(0.10-0.15)$ & $<0.001^{*}$ & $0.78(0.75-0.80)$ & $<0.001^{*}$ \\
\hline 9 & $0.11(0.08-0.13)$ & $<0.001^{*}$ & $0.85(0.82-0.87)$ & $<0.001^{*}$ \\
\hline 10 & $0.06(0.05-0.08)$ & $<0.001^{*}$ & $0.77(0.74-0.81)$ & $<0.001^{*}$ \\
\hline 11 & $0.05(0.03-0.08)$ & $<0.001^{*}$ & & \\
\hline 12 & $0.11(0.09-0.13)$ & $<0.001^{*}$ & & \\
\hline
\end{tabular}

Benin: 1 = Alibori, 2 = Atacora, $3=$ Atlantic, $4=$ Borgou, $5=$ Collines, $6=$ Couffo, $7=$ Donga, $8=$ Littoral, $9=$ Mono, $10=$ Oueme, $11=$ Plateau \& $12=$ Zou.

Zimbabwe: $1=$ Manicaland, $2=$ Manicaland Central, $3=$ Manicaland East, $4=$ Manicaland West, $5=$ Manicaland North, $6=$ Manicaland South, $7=$ Midlands, $8=$

Masvingo, $9=$ Harare $\& 10=$ Bulawayo.

*Significant at $p<0.05$

link between a disease and the possible prevention and control strategies.

The findings from both countries (Benin and Zimbabwe) showed that the disparities in terms of women's awareness of cervical cancer on the basis of age groups and across regions. The awareness level of women on cervical cancer differs in different geographical regions of Benin republic [34]. Previous studies reported that lack of awareness on cervical cancer was associated with poor cervical cancer screening practices in third-world countries $[4,24,35,36]$. Though the cost of cervical cancer services including its information in
Zimbabwe is reportedly high, centralized in urban settings, competing priorities, with limited resources confronting their healthcare system; there is a relatively marginal difference in the awareness of women on cervical cancer through the country's establishment of a policy framework to drive this agenda [37].

Furthermore, awareness of cervical cancer was also associated with women's age, educational level, household wealth quintile, religious belief, marital status, occupation and geographical region. Women who are engaged in professional, technical and managerial jobs have the capacity to understand various health information from 
different media platforms which could be attributed to the improved odds in awareness of cervical cancer. Such women could interact with different electronic gadgets such as android phones, computers, internet and so forth; which will avail them the opportunity to have increased awareness about cervical cancer. The same logic is applicable to women that are rich as compared with poor women. The differentials in the awareness level between Muslim women as compared to Christians could be attributed to the low level of education and cultural conservativeness among the Muslim folks. These could further affect their utilization of screening services including information regarding cervical cancer. Women that are currently married have continual and engaged visits to health facilities to access healthcare services which include those related to cervical cancer screening and care. These factors were also examined in a previous study [26]. These results suggest that an increase in women's educational level is effective in influencing awareness about diseases including cervical cancer. The findings could also suggest that as women's educational level increases, they are often more empowered with information and enlightened to understand more of their health issues including cervical cancer risk factors and prevention approaches $[29,38]$.

The study revealed the influence of age on the awareness level of cervical cancer in both settings. As women aged, they have the potential of increased awareness of various diseases that can affect women including cervical cancer which is consistent with the findings from the study by Mitiku \& Tefera [16] and a study in Nigeria that reported the influence of age on awareness of cervical cancer [39] as well as in Zimbabwe [37]. This can be attributed to their number of parity which includes antenatal care services where they have interactions with healthcare workers including health education sessions on maternal health and risk issues with dysfunctional national cervical cancer screening programme as well as the limited availability of screening centres [40]. Our results also were in agreement with a similar study in Zimbabwe, which showed that knowledge/awareness of cervical cancer was associated with having at least secondary education [41].

\section{Strengths and limitations}

The strength of this study is the use of current nationally representative datasets to measure prevalence and determinants of awareness cervical cancer in Benin and Zimbabwe. The findings make plausible comparison and are generalizable to women of reproductive age in both countries. However, the study utilized cross-sectional data, hence, only associations and no causal relationships are established. The unavailability of endogenous variables was another limitation in the use of secondary data.

\section{Conclusion}

There were disparities and potential barriers to the awareness levels on cervical cancer in Benin and Zimbabwe. The study revealed that socio-demographical factors including geographical location and selected economic factors greatly explained the unequal coverage of women awareness on cervical cancer in both countries. Overall, multi-sectoral approaches are recommended to address all the multifaceted factors with a view to improving people's awareness level on cervical cancer in resource-constrained settings.

\section{Acknowledgements \\ The authors appreciate the MEASURE DHS project for the approval and access to the original data.}

\section{Authors' contributions}

ME conceived and designed the study, performed data analysis and wrote the results, reviewed the literature, wrote the discussion of the findings. All authors contributed in the review of literature, the discussion of the findings, critically reviewed the manuscript for its intellectual content. ME had the responsibility to submit the manuscript. All authors read and approved the final manuscript.

\section{Funding}

This research received no grant from any funding agency in the public, commercial or not-for-profit sectors.

\section{Availability of data and materials}

Data for this study were sourced from Demographic and Health surveys

(DHS) and available here: http://dhsprogram.com/data/available-datasets.cfm.

Ethics approval and consent to participate

Ethics approval for this study was not required since the data is secondary and is available in the public domain. More details regarding DHS data and ethical standards are available at: http://dhsprogram.com/data/availabledatasets.cfm

\section{Consent for publication}

Demographic and Health Survey is a de-identified open-source dataset. Therefore, the requirement of consent for publication is not applicable.

\section{Competing interests}

The authors declare that the research was conducted in the absence of any commercial or financial relationships that could be construed as a potential conflict of interest.

\section{Author details}

${ }^{1}$ Department of Public \& Environmental Health, School of Medicine \& Allied Health Sciences, University of The Gambia, Kanifing, The Gambia. ${ }^{2}$ Project Management Unit, Management Sciences for Health, Abuja, Nigeria. ${ }^{3}$ Department of Community Health, Center of Excellence in Reproductive Health Innovation (CERHI), College of Medical Sciences, University of Benin, Benin City, Nigeria. ${ }^{4}$ Department of Epidemiology and Medical Statistics, Faculty of Public Health, College of Medicine, University of Ibadan, Ibadan, Nigeria.

Received: 25 December 2019 Accepted: 6 October 2020

Published online: 13 October 2020

\section{References}

1. Bray F, Ferlay J, Soerjomataram I, Siegel RL, Torre LA, Jemal A. Global cancer statistics 2018: GLOBOCAN estimates of incidence and mortality worldwide for 36 cancers in 185 countries. CA Cancer J Clin. 2018;68(6):394-424.

2. UNAIDS. It's time to make Cervical Cancer history. UNAIDS Feature story. 04 February 2019. 2019.

3. Bruni L, Albero G, Serrano B, Mena M, Gómez D, Muñoz J, Bosch FX de SS ICO/IARC Information Centre on HPV and Cancer (HPV Information Centre). 
Human Papillomavirus and Related Diseases in Benin. Summary Report 17 June 2019. 2019;(June).

4. World Health Organization (WHO). Comprehensive Cervical Cancer Control; A guide to essential practice 2 edition.

Httpswhointreproductivehealthtopicscancerhpv-Vaccininationen. 2014; 2nd Edition (December).

5. Rosa W. Transforming Our World: The 2030 Agenda for Sustainable Development. In: A New Era in Global Health. New York: Springer Publishing Company; 2017. [cited 2019 Feb 14]. Available from: http:// connect.springerpub.com/lookup/doi/10.1891/9780826190123.ap02.

6. Ntekim A. Cervical Cancer in sub Sahara Africa, topics on cervical cancer with an advoocacy for prevention. Dr R Rajamanickam Ed; 2012. p. 51-74.

7. Chin'ombe N, Sebata NL, Ruhanya V, Matarira HT. Human papillomavirus genotypes in cervical cancer and vaccination challenges in Zimbabwe. Infect Agent Cancer. 2014;9:16-9.

8. Globocan. Zimbabwe Source: Globocan 2018. The global cancer observatory. All Right Reserved-May, 2019. 2019

9. Bruni L, Barrionuevo-Rosas L, Alberto G, Serrano B, Valencia S, Brotons M, Mena M, Cosano R, Munoz J, Bosch FX, de Sanjose S CX. Human Papillomavirus and Related Diseases Report. ICO HPV Inf Cent. 2015:

10. Tapera O, Kadzatsa W, Nyakabau AM, Mavhu W, Dreyer G, Sjh H. Sociodemographic inequities in cervical cancer screening , treatment and care amongst women aged at least 25 years : evidence from surveys in Harare, Zimbabwe. BMC Public Health. 2019;19:1-12.

11. Globocan. Benin Source: Globocan 2018. The Global Cancer Observatory. All Right Reserved-May, 2019.

12. Corsi DJ, Neuman M, Finlay JE, Subramanian S. Demographic and health surveys: a profile. Int J Epidemiol. 2012;41(6):1602-13.

13. Short Fabic M, Choi Y, Bird S. A systematic review of demographic and health surveys: data availability and utilization for research. Bull World Health Organ. 2012;90(8):604-12.

14. Republic of Benin - Country Profile. Benin - Country Profile - Nations Online Project. [cited 2019 Dec 13]. Available from: http://www.nationsonline.org/ oneworld/benin.htm.

15. Ploch L. Zimbabwe: Background - congressional research service; 2010. p. 52.

16. Mitiku I, Tefera F. Knowledge about cervical cancer and associated factors among 15-49 year old women in Dessie town, Northeast Ethiopia. Paraskevis D, editor. PLOS ONE. 2016;11(9):e0163136.

17. Ayinde OA, Ogunbode OO, Adebayo OJ. Determinants of cervical cancer knowledge and the utilisation of screening among a Nigerian female population. Trop J Obstet Gynaecol. 2005;22(1):21-24-24.

18. Moshi FV, Vandervort EB, Kibusi SM. Cervical cancer awareness among women in Tanzania: an analysis of data from the 2011-12 Tanzania HIV and malaria indicators survey. Int J Chronic Dis. 2018;7.

19. Rutstein SO, Staveteig S. Making the demographic and health surveys wealth index comparable; 2014. p. 43.

20. Hruschka DJ, Gerkey D, Hadley C. Estimating the absolute wealth of households. Bull World Health Organ. 2015;93(7):483-90.

21. Midi H, Sarkar SK, Rana S. Collinearity diagnostics of binary logistic regression model. J Interdiscip Math. 2010;13(3):253-67.

22. Williams R. Using the margins command to estimate and interpret adjusted predictions and marginal effects. Stata J Promot Commun Stat Stata. 2012; 12(2):308-31.

23. Perlman $\mathrm{S}$, Wamai RG, Bain PA, Welty T, Welty E, Ogembo JG. Knowledge and awareness of HPV vaccine and acceptability to vaccinate in SubSaharan Africa: a systematic review. Hozbor DF, editor. PLOS ONE. 2014;9(3): e90912.

24. World Health Organization, editor. Cervical cancer screening in developing countries: report of a WHO consultation. Geneva: World Health Organization; 2002. p. 75.

25. Balogun MR, Odukoya OO, Oyediran M, Ujomu P. Cervical cancer awareness and preventive practices: a challenge for female urban slum dwellers in Lagos, Nigeria. Afr J Reprod Health. 2012;16(1):75-82.

26. Aweke YH, Ayanto SY, Ersado TL. Knowledge, attitude and practice for cervical cancer prevention and control among women of childbearing age in Hossana Town, Hadiya zone, Southern Ethiopia: Community-based crosssectional study. Robboy SJ, editor. PLOS ONE. 2017;12(7):e0181415.

27. Bathija G, Mallesh S, Gajula M. A study on awareness of cervical cancer among women of reproductive age group in urban slums of old Hubli, Karnataka, India. Int J Community Med Public Health. 2016:2579-83.
28. Naik DD, Donta B, Nair S, Mali BN. Awareness of sexually transmitted infections and cervical cancer among women in urban slums of Mumbai, Maharashtra, India. Int J Community Med Public Health. 2017;4(2):400.

29. Olubodun T, Odukoya OO, Balogun MR. Knowledge, attitude and practice of cervical cancer prevention, among women residing in an urban slum in Lagos, South West, Nigeria. Pan Afr Med J. 2019;32 [cited 2019 Oct 26]. Available from: http://www.panafrican-med-journal.com/content/ article/32/130/full/.

30. Dutta MJ. Health information processing from television: the role of health orientation. Health Commun. 2007;21(1):1-9.

31. Dutta-Bergman MJ. Primary sources of health information: comparisons in the domain of health attitudes, health cognitions, and health behaviors. Health Commun. 2004;16(3):273-88.

32. Schwitzer G, Mudur G, Henry D, Wilson A, Goozner M, Simbra M, et al. What are the roles and responsibilities of the media in disseminating health information? PLoS Med. 2005;2(7):8.

33. Moynihan R, Bero L, Ross-Degnan D, Henry D, Lee K, Watkins J, et al. Coverage by the news media of the benefits and risks of medications. $\mathrm{N}$ Engl J Med. 2000;342(22):1645-50.

34. Piras F, Piga M, De Montis A, Zannou AR, Minerba L, Perra MT, et al. Prevalence of human papillomavirus infection in women in Benin. West Africa Virol J. 2011:8(1):514

35. Finocchario-Kessler S, Wexler C, Maloba M, Mabachi N, Ndikum-Moffor F, Bukusi E. Cervical cancer prevention and treatment research in Africa: a systematic review from a public health perspective. BMC Womens Health. 2016;16(1):29.

36. Drolet M, Bénard É, Boily M-C, Ali H, Baandrup L, Bauer H, et al. Populationlevel impact and herd effects following human papillomavirus vaccination programmes: a systematic review and meta-analysis. Lancet Infect Dis. 2015; 15(5):565-80.

37. Tapera O, Dreyer G, Kadzatsa W, Nyakabau AM, Stray-Pedersen B, Hendricks SJH. Determinants of access and utilization of cervical cancer treatment and palliative care services in Harare, Zimbabwe. BMC Public Health. 2019;19(1):1018.

38. Tapera O, Dreyer G, Kadzatsa W, Nyakabau AM, Stray-Pedersen B, Sjh H. Cervical cancer knowledge, attitudes, beliefs and practices of women aged at least 25 years in Harare, Zimbabwe. BMC Womens Health. 2019;19(1):91.

39. Ayinde OA, Ogunbode OO, Adebayo OJ. Determinants of cervical cancer knowledge and the utilisation of screening among a Nigerian female population. Trop J Obstet Gynaecol. 2006;22(1):21-4.

40. Ziba F, Baffoe P, Dapare P, Shittu S, Antuamwine B. Awareness and knowledge level of cervical cancer among women of reproductive age in Bolgatanga municipality. J Med Biomed Sci. 2015;4(2):1.

41. Mutambara J, Mutandwa P, Mahapa M, Chirasha V, Nkiwane S, Shangahaidonhi T. Knowledge, attitudes and practices of cervical cancer screening among women who attend traditional churches in Zimbabwe. J Cancer Res Pract. 2017:4(2):53-8.

\section{Publisher's Note}

Springer Nature remains neutral with regard to jurisdictional claims in published maps and institutional affiliations.

Ready to submit your research? Choose BMC and benefit from:

- fast, convenient online submission

- thorough peer review by experienced researchers in your field

- rapid publication on acceptance

- support for research data, including large and complex data types

- gold Open Access which fosters wider collaboration and increased citations

- maximum visibility for your research: over $100 \mathrm{M}$ website views per year

At $\mathrm{BMC}$, research is always in progress.

Learn more biomedcentral.com/submission 